\title{
Improvement of health-related quality of life and psychological well-being after HCV eradication with direct-acting antiviral agents. Real life setting data of an Italian cohort valued by Hepatitis Quality of Life Questionnaire (HQLQv2)
}

\author{
Gaetano Bertino, ${ }^{1}$ Rosalia Ragusa, ${ }^{2}$ Liberato Simone Corsaro, ${ }^{3}$ Evelise Frazzetto, ${ }^{1}$ \\ Vincenzo Messina, ${ }^{4}$ Lucio Inguscio, ${ }^{5}$ Carlo Lai, ${ }^{5}$ Marilena Maglia, ${ }^{6}$ Andrea Nunnari, ${ }^{7}$ \\ Pasquale Caponnetto 6
}

\begin{abstract}
${ }^{1}$ Hepatology Unit, Policlinic "G. Rodolico", Department of Clinical and Experimental Medicine, University of Catania; ${ }^{2}$ Health Technology Assessment Committee, University Hospital "G. Rodolico", Catania; ${ }^{3}$ Biologist, Master of Science in Clinical Trial Governance, University of Catania; 4 Infectious Disease Unit, Azienda Ospedaliera "S. Anna e S. Sebastiano" of Caserta; ${ }^{5}$ Department of Dynamic and Clinical Psychology, University of Rome La Sapienza, Rome; ${ }^{6}$ Center of Excellence for the Acceleration of Harm Reduction (CoEHAR), Department of Clinical and Experimental Medicine, University of Catania; ${ }^{7}$ School of Medicine, Course of Rehabilitation Science for Health Professions, Università di Catania, Italy
\end{abstract}

\section{Abstract \\ HCV (Hepatitis C Virus) decreases Health-Related Quality of}

Correspondence: Lucio Inguscio, Department of Dynamic and Clinical Psychology, University of Rome La Sapienza, Rome, Italy.

Tel: +393406254046

E-mail: lucio.inguscio@uniroma1.it

Key words: Health care; health psychology; QoL; phycological wellbeing; illness perception; chronic illness.

Contributions: The authors contributed equally.

Conflict of interest: The authors declare that they have no conflict of interest.

Funding: This study was funded by the 2016/2018 Research Plan of University of Catania, Department of Clinical and Experimental Medicine (project \#A "Early molecular and clinical-instrumental markers in metabolic and chronic-degenerative pathologies").

Ethical approval and consent to participate: The study was conducted in accordance with the Declaration of Helsinki and ethical standards established by the Italian National Psychological Association.

Consent for publication: All patients signed an institutional consensus for publication.

Availability of data and materials: The datasets used and/or analyzed during the current study are available from the corresponding author on reasonable request. All data generated or analyzed during this study are included in this published article.

Received for publication: 3 November 2020.

Revision received: 5 December 2020.

Accepted for publication: 5 December 2020.

This work is licensed under a Creative Commons AttributionNonCommercial 4.0 International License (CC BY-NC 4.0).

(C) Copyright: the Author(s), 2020

Licensee PAGEPress, Italy

Health Psychology Research 2020; 8:9450

doi:10.4081/hpr.2020.9450
Life with detriments to physical, mental and social health domains. Interferon and Ribavirin treatment is associated with depression and anxiety that further impairs HRQoL (HealthRelated Quality of Life). IFN-free (interferon-free) regimes (Direct Acting Antivirals, DAAs) are safe and highly effective drugs, with improvement also of HRQoL and related Psychological Well-Being. Our aim is to describe how the latest generation IFN-free treatment can change quality of life and related Psychological Well-Being in Italian Chronic Hepatitis C/Cirrhosis affected patients. SF-36v2 (Short Form Health Survey is a 36-item, patient-reported survey of patient health) - HQLQv2 (Hepatitis Quality of Life Questionnaire) was administered at two time points: baseline $(n=72)$ and 12 weeks after the end of therapy $[n=72, S V R=72$ - Sustained Virologic Response (SVR)]. Patients with chronic HCV undergoing DAAs treatment from two Italian centers were enrolled. The overall average of the answers is configured for most of the domains that make up the questionnaire, with scores above 50 . The quality of life of this sample is very close to the average of the US population, with a minimum average score of 45.9 for the Role Emotional scale and an average maximum score of 56.4 for the Vitality scale. Both are significant results from statistical analysis. It seems that DAAs treatment therapy does not affect but improves the general quality and psychological state of adult patients with Chronic HCV infection.

\section{Introduction}

Starting on 2011 the landscape of $\mathrm{HCV}$ (hepatitis C virus) therapy has experienced a real revolution (Bansal, Singal, McGuire \& Anand, 2015; Bertino et al., 2016). The improvement of molecular biology techniques has allowed us to perfectly understand viral infection and replication, so IFN-based (interferonbased) treatments were definitively dismissed to develop and introduce in clinical practice IFN-free (interferon-free) treatments thanks to Direct-acting Antiviral Agents (DAAs) [Bertino et al., 2016; American Association for the Study of Liver Disease (AASLD), 2017].

The aim of therapy is eradication of HCV that slows the pro- 
gression of liver disease and improves the survival, by reducing the risk of decompensation and liver cancer (AASLD, 2017). The endpoint of therapy is undetectable HCV-RNA in serum or plasma by a sensitive assay (lower limit of detection $\leq 15 \mathrm{IU} / \mathrm{ml}$ ) 12 weeks (SVR12, Sustained Virological Response 12) or 24 weeks (SVR24, Sustained Virological Response 24) after the End of Treatment (EOT) (AASLD, 2017).

Sustained Virological Response (SVR) indicates the eradication of $\mathrm{HCV}$ and has many hepatic benefits: improves liver necroinflammation, fibrosis, reduces also risk of HCC (Hepatitis C Cancer), hepatic decompensation and liver-related mortality (Cabibbo et al., 2019; Wei \& Huang, 2019).

DAAs are safe and effective drugs, with SVR rates above 9798\% (according to HCV genotype and comorbidity) (Bertino et al., 2018; Cabibbo et al., 2017; Calvaruso et al., 2018; Calvaruso et al., 2019; Corsaro and Ragusa, 2018;).

DAAs therapy has also a shorter duration than IFN-based therapy, only 8 or 12 weeks, according to HCV genotypes, staging of liver fibrosis (F1-F4), comorbidity (drug-drug interactions), renal function [European Association for the Study of the Liver (EASL), 2018].

Furthermore, HCV eradication has many extrahepatic benefits: improves extrahepatic manifestations (e.g. cryoglobulinemic syndromes, lymphoproliferative B-cell syndromes) and non-specific symptoms such as fatigue, nausea, abdominal pain, weight loss (Kuna, Jakab, Smolic, Wu and Smolic, 2019; Polo and Laufer, 2017).

Patients with chronic HCV infection are more likely to develop insulin resistance and diabetes, cognitive dysfunction and depression (Kuna et al., 2019).

A health-related definition of Quality of Life (HRQoL) is developed taking into account health-related aspects of QoL (Quality of Life). The WHO (World Health Organization) (2014) defines HRQoL as "those aspects of self-perceived well-being that are related to or influenced by the presence of disease or treatment". This concept is sometimes expressed in a narrower sense, in which HRQoL "is used to identify the subset of the important or the most common ways in which health or health care affects wellbeing" (Ebrahim, 1995). Another aspect to consider for HRQoL is the value of health. HRQoL can be tied to "values as signed for different states of integrity" (Peasgood, Brazier, Mukuria and Rowen, 2014).Other research was based on health questionnaires in which a significant improvement in quality of life scores was closely linked to a sustained viral response (Bernstein, Kleinman, Barker, Revicki and Green, 2002; Gold et al., 1996), especially in those patients with chronic hepatitis.

The change in HRQoL in HCV-infected patients who are treated with IFN appears to be due to the IFN itself which being proinflammatory cytokine inducing neuropsychiatric symptoms. Therefore, a percentage of subjects between $12 \%$ and $41 \%$ affected by chronic hepatitis and treated with IFN develop neuropsychiatric symptoms, even if these events did not belong to the patient's natural history (McHutchison et al., 2002). This percentage increases, involving from $17 \%$ to $58 \%$ of patients, with symptoms mainly related to depression, if there had been a neuropsychiatric syndrome in the patient's history (McHutchison et al., 2002) as consequence IFN- $\alpha$ could be associated with psychiatric adverse effects which can also worsen existing psychiatric conditions (Horsmans, 2006; Quelhas and Lopes, 2009). In addition, depression or related symptoms develop more frequently during IFN- $\alpha$ therapy, with over $25 \%$ of patients receiving IFN- $\alpha$ therapy showing treatmentinduced depression (Keefe, 2007).

Works aimed at assessing the quality of life, conducted using the health questionnaire, show that interferon regimens impair physical and mental health (Mandorfer et al., 2014). In contrast to IFN-based regimens, highly effective and well-tolerated IFN-free regimens improve HRQoL already during treatment (Scheiner et al., 2016). The arrival of direct-acting antivirals, which boast relatively high efficacy, low toxicity and high prices, requires the use of disease-sensitive HRQoL measures so that action can be taken promptly in the choice of treatment (Bethea, Chen, Hur, Chung and Chhatwal, 2018; Corsaro and Ragusa, 2018). Altogether, a successful treatment generates a containment of liver-related morbidity and an improvement in health-related quality of life (Ragusa et al., 2018; Younossi and Henry, 2015).

This work focused on the impact that virus-related factors have on HRQoL and what type of impact direct antivirals, used on patients with chronic hepatitis $\mathrm{C} /$ cirrhosis, have on their HRQoL and Psychological Well-Being.

\section{Methods}

\section{Study population and medical treatment}

During a period of 12 months (from February 2018 to February 2019) adult patients with Chronic HCV infection, 7 cirrhotic and 163 non-cirrhotic, were enrolled for treatment with DAAs in two Italian Hospitals: i) Hepatology Unit, Azienda Ospedaliero Universitaria "Policlinico - Vittorio Emanuele" of Catania, and ii) Infectious Disease Unit, Azienda Ospedaliero "S. Anna e S. Sebastiano" of Caserta.

Before treatment, each patient had undergone to staging of liver disease (blood chemistry tests, Ultrasonography, Transient Elastography, and esophagogastroduodenoscopy) and to a virological evaluation (HCV genotype and serum viral load, HBV and HIV co-infection).

The diagnosis of cirrhosis included at least one of the following criteria: previous liver biopsy, a liver stiffness $>12 \mathrm{kPa}$ at Transient Elastography, or esophageal and/or gastric varices. Functional class of Cirrhosis was attributed with Child-Pugh score, all patients (7) with cirrhosis were in a Child-Pugh score A.

HCV-RNA levels were determined with real-time PCR-based assays (Roche TaqMan; LLOD $15 \mathrm{IU} / \mathrm{mL}$ ) and were evaluated: before treatment (baseline); at weeks 8 or 12 of therapy (end of therapy, EOT);12 weeks after EOT (Sustained Virological Response 12 weeks, SVR 12).

The Hepatitis Quality of Life Questionnaire (HQLQv2TM) was selected to assess Quality of life and Psychological Well-being and administered to all patients before treatment (baseline, T0) and 12 weeks after the end of therapy (SVR12, T1).

\section{Measures}

The Hepatitis Quality of Life Questionnaire (HQLQ), version 2 (HQLQv2), was used to assess both generic and disease-specific elements of Quality of Life and Psychological Well-Being (Bayliss et al., 1998). The HQLQ includes the Short Form-36 version 2 items (which can be used to assess generic aspects of health status) and four hepatitis-specific health domain scores: health distress (HD, 4 items), positive well-being (PWB, 4 items), hepatitis-specific limitations (HLIM, 3 items) and hepatitis-specific health distress (HHD, 4 items). The original authors designed the SF-36 to measure health at the individual level in clinical practice and research, and at the population level for health policy evaluations, and general population surveys (Ware Jr. \& Sherbourne, 1992). It 
has been used in thousands of research studies (Lins and Carvalho, 2016) and was originally designed as a generic health measure but has also been applied to specific disease populations.

The SF-36 version 2 (SF-36v2) questionnaire (Ware et al., 1995 ) is a self-administered questionnaire comprised of a total of 36 items with two (physical and mental) components. The Physical Component Summary (PCS) and the Mental Component Summary (MCS) include four domains respectively. The physical health measure includes four scales of physical functioning (PF, 10 items), role-physical (RP, 4 items), bodily pain (BP, 2 items), and general health (GH, 6 items). The mental health measure is composed of vitality (VT, 4 items), social functioning (SF, 2 items), role-emotional (RE, 3 items), and mental health ( $\mathrm{MH}, 5$ items).

Optum Life Sciences licensed the usage of the questionnaire survey. By using the standard IQOLA translation methodology (Bullinger et al., 1998), translation from English to Italian was performed by Pasquale Caponnetto, Evelise Frazzetto and Marilena Maglia, and approved by Optum (Office of Grant and Scholary Research - Johnston, RI, USA).

Internal consistency reliability of the SF-36v2 and HQLQv2 was determined from Cronbach's alpha $(\alpha)$ of each of the 8 domains and item-scale correlation (corrected for overlap). Spearman's correlation was used to determine the correlation between items and scales (Alhaji et al., 2018).

Each raw domain score can be converted into a 0-100 scale, with a higher score indicating a higher health status (i.e., a score of 0 indicates the least favorable health status; a score of 100 , the most favorable health status). To obtain this type of score, the answers to the HQLQv2 questionnaire have been converted into a numerical likert scale (for example, 0: "always", 1: "often", 2: "from time to time", 3: "rarely ", 4: "never"). That data was introduced in an Excel file (.csv) which has been shared with Optum Life Sciences ${ }^{\circledR}$ [QualityMetric (Canada) Inc.] via Accellion (secure file sharing platform).

QualityMetric Health Outcome Scoring Software (QualityMetric, Lincoln, RI) performed final score of each domain and scale that was shared with us via Accellion.

The file that QualityMetric shared with us contains another scale called NBS (Norm Based Score). These are the SF-36v2 scale scores normed to the United States population to have a mean of 50 and standard deviation of 10.

For all summary and domain scores, higher scores indicate greater quality of life. For generic summary and domain scores, differences between groups of 3 and 5 points, respectively, represent clinically meaningful differences (Maruish, 2011).

\section{Statistical methods}

The Statistical Package for the Social Sciences V 25.0 (IBM Corp. Released 2017. IBM SPSS Statistics for Windows, Version 25.0. Armonk, NY: IBM Corp.) was used for the data analysis. Descriptive statistics were computed to summarize data. Individual variables were examined by percentages, means, and standard deviations (SDs). Differences between pre and post treatment results were assessed with analysis of mean difference between posttest score and pretest score $(d)$, standard deviation of the difference between posttest score and pretest score (SD) and analysis of standardized response mean (SRM). This index was calculated as $d / \mathrm{SD}$ (Zhou et al., 2013). We explained the SRM index also with a paired-samples $t$-test.

To measure the reliability of psychometric tests we use Cronbach's alpha, also called alpha $(\alpha)$. Internal consistency reliability was measured by Cronbach's a, with the value greater than 0.70 representing acceptable reliability. Test-retest reliability was measured by Intra-Class Correlation (ICC) between the 12-weeks test-retest results. ICC $<0.40$ is considered poor to fair agreement, 0.41 to 0.60 moderate agreement, 0.61 to 0.80 good agreement, and $>0.80$ excellent agreement (Bartko, 1966). We also calculated Spearman's correlation coefficients for all scales.

The calculation will refer to all scale dimensions: SF-36v2 (pre and post) SF-36v2NBS (pre and post), SF-36v2 Component summaries (pre-post), and HQLQv2 (pre-post).

A multivariate analysis of the data was carried out to determine the possible significance of the sex factor in the evaluation of the results. In particular, the "Trace of Pillai", the "Lambda of Wilks", the "Trace of Hotelling". Furthermore, the "Greater Roy's Root" and the "Mauchly's Spherical Test" were used.

\section{Results}

\section{Characteristics of participants}

A total of 72 patients completed the HQLQv2 before the initiation and at the end of their DAA treatments at two Italian hospital centers.

All patients complete the treatment, without serious adverse events, drop out or withdraw therapy or death (liver- and no liverrelated) and the rate of Sustained Virological Response was 100\%.

The demographic and medical characteristics revealed that the mean age of the sample $(n=72)$ was $62.28 \pm$ [Standard Deviation (SD) 13.53]. The sample contained a different percentage of males $(61 \%)$ and females $(39 \%)$. The majority of participants $(90.3 \%)$ showed chronic HCV related hepatitis (CHC) with $9.7 \%$ affected by liver cirrhosis.

The individuals considered by our study with a genotype different from genotype 1, represent $29.2 \%$ of the population. They were distributed as follows: $15.3 \%$ with genotype $2,11.1 \%$ with genotype 3 and $2.8 \%$ with genotype $4.43 .1 \%$ of participants presented medical comorbidities at risk of progression of liver damage [chronic non-viral liver diseases, diabetes mellitus in drug treatment, obesity (body mass index $\geq 30 \mathrm{~kg} / \mathrm{m}^{2}$ ), hemoglobinopathies and congenital coagulopathies]. Finally, 25\% of patients had hepatic steatosis, of which $33.3 \%$ had mild hepatic steatosis.

\section{Scoring analysis}

For each item of the questionnaire, the results in terms of improvement, deterioration and stagnation (or status quo) comparing the score provided to us by Optum ${ }^{\circledR}$ between $\mathrm{T} 0$ and $\mathrm{T} 1$, showed that for most of the domains there was a score increasing after DAA treatments (“improvement" or "improv.", Figure 1) suggesting an overall improvement Quality of Life and Psychological Well-Being.

It should be noted that most of those who had the same constant score between T0 and T1 had a high score (T0) and maintained it even after therapy (T1) ("stable"). This suggests that therapy did not deteriorate the quality of life Quality of Life and Psychological Well-Being of this group of patients or significantly influence those who already had a good parameter.

\section{Statistical analysis}

The average scores for most of the individual domains at $\mathrm{T} 1$ are higher than those at time $\mathrm{T} 0$. This reflects the scoring analysis seen in the Table 1.

Comparing with the US population, given that there is an 
Table 1. The responsiveness of the SF-36v2 and the HQLQ: scores (mean \pm SD), ^d (average mean difference), Sd (standard deviation of difference) and standardized response mean (SRM) stratified on improvement, status quo, or deterioration in health status.

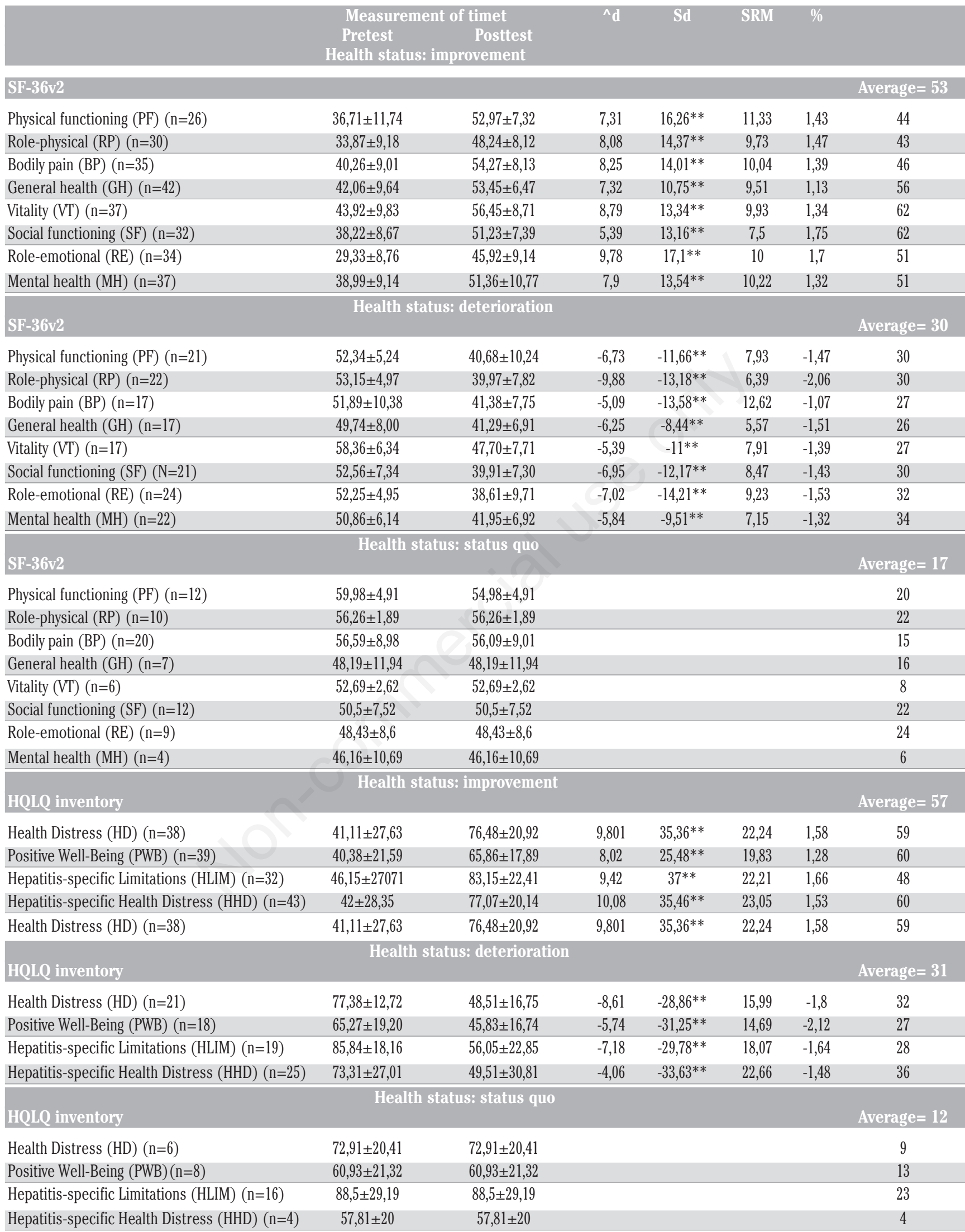

SD: standard deviation. ${ }^{\wedge} \mathrm{d}$ : mean difference between posttest score and pretest score. Sd: standard deviation of the difference between posttest score and pretest score. SRM: standardized response mean was calculated as $/ \mathrm{Sd}$. The $\mathrm{SRM} \geq 1.00$ was in bold. Paired-samples t-test: ${ }^{*} \mathrm{P}<0.05{ }^{* *} \mathrm{P}<0.01$. 
Values estimated by the Cronbach's alpha were satisfactory for the Physical Components, except for the General Health sub-scale. In the Mental Component, only the Role Emotional Scale has an alpha $=0.94$ and a ICC index $=0.89$. In Vitality, General Health and Social Functioning Scales, alpha observed was not reliable and a total-item score correlation was not observed (Table 2).

The last four pre-therapy domains examined (HD, PWB, HLIM, HHD) included those related to the liver pathology examined. Here Cronbach's alpha was equal to: 0.9 (HD), 0.86 (PWB), 0.95 (HLIM), 0.94 (HHD) so the scores were reliable. The alpha for the same four post-therapy domains was equal to 0.9 (HD), 0.85 (PWB), 0.94 (HLIM), 0.93 (HHD) so that reliability was reached also in this case. For this last group the reliability was more than good for the pre-therapy results (being higher than 0.8 ) while it is more than fair almost good for the results obtained in the post-therapy. Table 3 shows Spearman's correlation coefficients calculated as other test-retest index (Spearman's correlation coefficients tot. 0,538).

The ANOVA (Analysis of Variance) for all scales taken into consideration, namely SF-36v2 (pre and post) SF-36v2NBS (pre and post), SF-36v2 Component summaries (pre and post) HQLQv2 (pre and post), can always be superimposed with the average of the various variables and domains belonging to each scale. Further confirming the reliability of the results obtained. Finally, multivariate tests were used to verify if the gender factor could have a role in the perception of improvement or deterioration in the quality of life and associated psychological well-being. This aspect is potentially significant, as it is well known that women perceive pain differently than men (Belfer, 2017; Pieretti et al., 2016).

For these reasons, the "Trace of Pillai", the "Lambda of Wilks", the "Trace of Hotelling", the "Root of Greater Roy" and ity of the measure, the ICC was used, considering evidence of stability ICC $>0.70$.

\section{N. of patients in HQLQ scales}

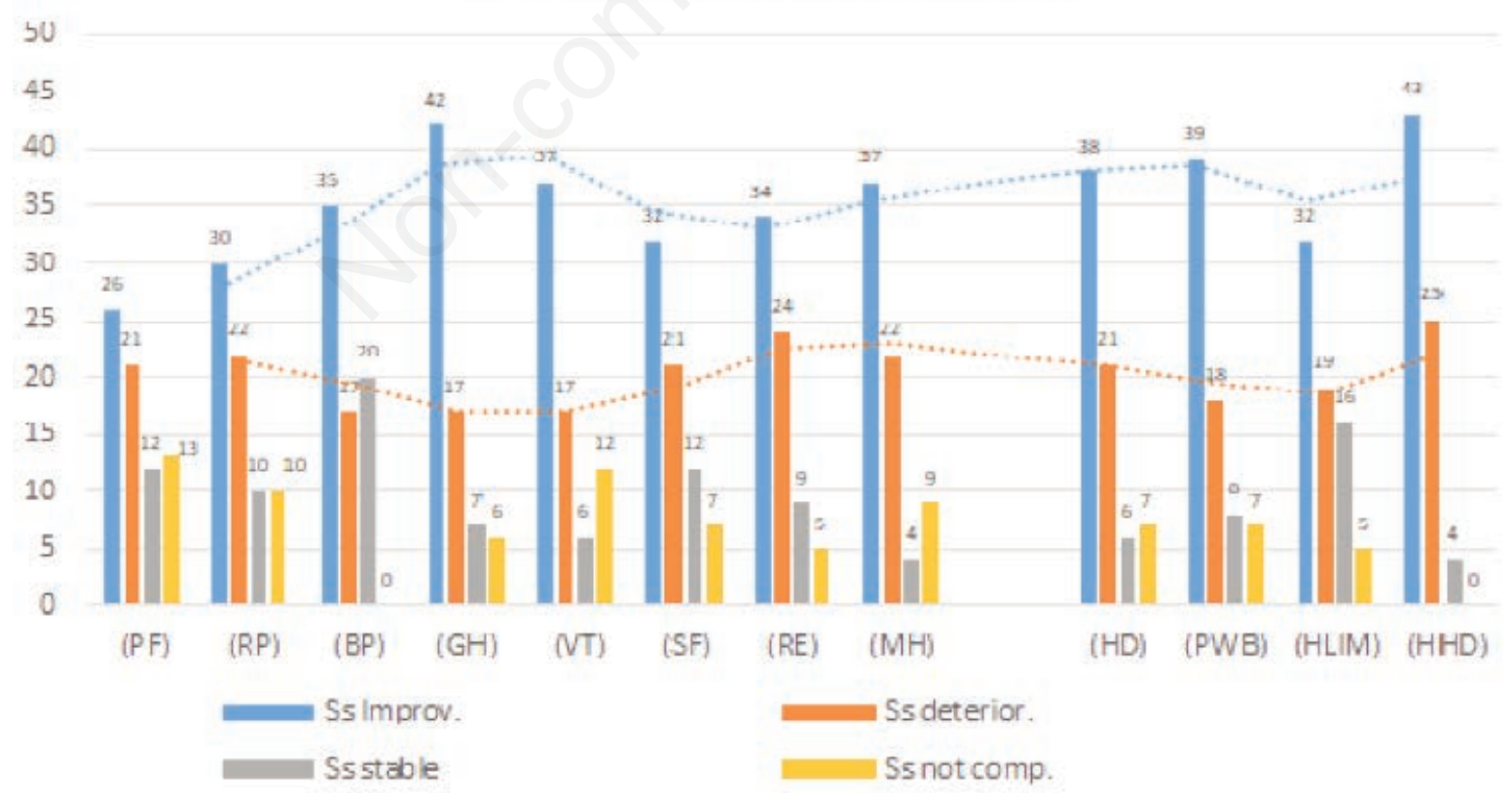

Figure 1. Score analysis: improve involves the greatest number of patients in most of the domains. Legend: PF: Physical Functioning; RP: Role Physical; BP: Bodily Pain; GH: General Health; VT: Vitality Scale; SF: Social Functioning; RE: Role Emotional; MH: Mental Health; PCS: Physical Component Summary; MCS: Mental Component Summary; HD: Health Distress; PWB: Positive Wellbeing; HLIM: Hepatitis-specific Limitation; HHD: Hepatitis-specific Health Distress. 
the "Test of Sphericity of Mauchly" were used. These statistical tests were performed on the scores for the first and second administration of the "HQLQv2" questionnaire taking into consideration the gender. All statistical tests showed that the gender factor, relative to our sample, is not significant in the perception of an improvement or deterioration in post-administration quality of life and associated psychological well-being of DAAs.

\section{Discussion and conclusions}

$\mathrm{HCV}$ infection reduces the quality of life and psychological well-being of chronically affected patients. Among the various symptoms, in addition to the physical ones, there are depression, fatigue, anxiety and mental deterioration, and psychological and psychopathological factors such as mood, emotion, affective state and anxiety in chronic physical conditions can have an important

Table 2. Item-total correlation, Cronbach's alpha coefficient and valid case of HQLQ inventory.

\begin{tabular}{|c|c|c|c|c|c|c|c|}
\hline SF36v2 Scale & $\begin{array}{l}\text { Item (n) } \\
\text { correlation }\end{array}$ & $\begin{array}{c}\text { Item-total } \\
\text { Alpha }\end{array}$ & $\begin{array}{l}\text { Cronbach's } \\
\text { Alpha } \\
\text { (if item deleted) }\end{array}$ & $\begin{array}{c}\text { Cronbach's } \\
\text { Case }\end{array}$ & Valid & ICC & IC95\% \\
\hline $\begin{array}{l}\text { Physical Functioning (PCS) } \\
\text { Item } 1 \\
\text { Item } 2 \\
\text { Item } 3 \\
\text { Item } 4 \\
\text { Item } 5 \\
\text { Item } 6 \\
\text { Item } 7 \\
\text { Item } 8 \\
\text { Item } 9 \\
\text { Item } 10\end{array}$ & 10 & $\begin{array}{l}0.689 \\
0.843 \\
0.828 \\
0.817 \\
0.884 \\
0.808 \\
0.814 \\
0.850 \\
0.768 \\
0.757\end{array}$ & 0.953 & $\begin{array}{l}0.954 \\
0.947 \\
0.947 \\
0.948 \\
0.946 \\
0.949 \\
0.948 \\
0.947 \\
0.950 \\
0.951\end{array}$ & 63 & 0.7 & $0.6-0.75$ \\
\hline $\begin{array}{l}\text { Role-Physical (PCS) } \\
\text { Item } 11 \\
\text { Item } 12 \\
\text { Item } 13 \\
\text { Item } 14 \\
\end{array}$ & 4 & $\begin{array}{l}0.912 \\
0.878 \\
0.858 \\
0.885\end{array}$ & 0.950 & $\begin{array}{l}0.939 \\
0.941 \\
0.933 \\
0.939\end{array}$ & 66 & 0.83 & $0.77-0.88$ \\
\hline $\begin{array}{l}\text { Bodily Pain (PCS) } \\
\text { Item } 15 \\
\text { Item } 16\end{array}$ & 2 & $\begin{array}{l}0.816 \\
0.816\end{array}$ & 0.889 & $\begin{array}{l}0.948 \\
0.950\end{array}$ & 71 & 0.81 & $0.72-0.88$ \\
\hline General Health (PCS) from item 17 to 22 & 6 & Not reliable & & & & & \\
\hline Vitality (MCS) from item 23 to 26 & 4 & Not reliable & & & 68 & & \\
\hline Social Functioning (MCS) item 27-28 & 2 & Not reliable & & & 72 & & \\
\hline $\begin{array}{l}\text { Role-Emotional (MCS) } \\
\text { Item } 29 \\
\text { Item } 30 \\
\text { Item } 31\end{array}$ & 3 & $\begin{array}{l}0.924 \\
0.938 \\
0.888\end{array}$ & 0.944 & $\begin{array}{l}0.895 \\
0.921 \\
0.937\end{array}$ & 69 & 0.89 & $0.78-0.89$ \\
\hline Mental Health (MCS) from item 32 to 36 & 5 & Not reliable & & & & & \\
\hline \multicolumn{8}{|l|}{ HQLQ2v Scale } \\
\hline $\begin{array}{l}\text { Health distress } \\
\text { Item } 1 \\
\text { Item } 2 \\
\text { Item } 3 \\
\text { tem } 4\end{array}$ & 4 & $\begin{array}{l}0.782 \\
0.835 \\
0.763 \\
0.796\end{array}$ & 0.9 & $\begin{array}{l}0.885 \\
0.865 \\
0.890 \\
0.881\end{array}$ & 70.000 & 0.71 & $0.61-0.79$ \\
\hline $\begin{array}{l}\text { Positive well-being } \\
\text { Item } 5 \\
\text { Item } 6 \\
\text { Item } 7 \\
\text { Item } 8\end{array}$ & 4 & $\begin{array}{l}0.672 \\
0.764 \\
0.817 \\
0.650\end{array}$ & 0.86 & $\begin{array}{l}0.850 \\
0.814 \\
0.794 \\
0.867\end{array}$ & 69.000 & 0.7 & $0.61-0.72$ \\
\hline $\begin{array}{l}\text { Hepatitis specific limitations } \\
\text { Item } 9 \\
\text { Item } 10 \\
\text { Item } 11 \\
\end{array}$ & 3 & $\begin{array}{l}0.860 \\
0.944 \\
0.901\end{array}$ & 0.95 & $\begin{array}{l}0.962 \\
0.898 \\
0.931\end{array}$ & 70.000 & 0.87 & $0.81-0.93$ \\
\hline $\begin{array}{l}\text { Hepatitis-specific health distress } \\
\text { Item } 12 \\
\text { Item } 13 \\
\text { Item } 14 \\
\text { Item } 15 \\
\text { Item } 16 \\
\end{array}$ & 5 & $\begin{array}{l}0.916 \\
0.789 \\
0.749 \\
0.857 \\
0.916 \\
\end{array}$ & 0.94 & $\begin{array}{l}0.915 \\
0.937 \\
0.944 \\
0.926 \\
0.915\end{array}$ & 70 & 0.72 & $0.68-0.83$ \\
\hline
\end{tabular}


role on medical symptom burden (Caponnetto, Lai, Maglia \& Cosci, 2020; Katon, Lin \& Kroenke 2007) and on health behaviors such as adherence (Di Matteo, Lepper \& Croghan, 2000) so a pharmacotherapy that doesn't alter the psychological balance is of great importance (Caponnetto et al., 2020).

Through the HQLQv2 scores analysis and the statistical results, it was shown that, overall, the participants' general state of health improved at the end of the drug therapy (carried out with three antiviral drugs combinations: Sofosbuvir - Velpatasvir; Glecaprevir - Pibrentasvir and Elbasvir - Grazoprevir) and suggested that the participants' quality of life examined is projected towards improving the overall functioning at the social, work, physical, psychological and other areas examined by the HQLQv2 questionnaire.

These statistical results, together with the proximity of the scores obtained with respect to the average US population, confirm that our sample, although not large, is representative.

Finally, although the literature demonstrates a different perception of physical pain related to gender, this does not emerge in this study. Our patients, in fact, did not show a particular difference, linked to gender, in providing their perception, for each of the variables taken into consideration by the questionnaire.

Two important limitations of this study are the not large sample size and the large number of variables in relation to the number of participants and the many different treatment schedules.

In conclusion, results support the observation that patients exposed to DAAs generally maintain the pre-treatment baseline score three months after completing antiviral therapy, or even exceed it. This once again expresses the safe profile of this intensive treatment, regardless of the antiviral used and/or the duration of the treatment. Before and after DAAs treatment in patients with chronic HCV infection, health-related quality of life and the associated psychological well-being did not appear to be affected by the presence of cirrhosis, age, and gender. Furthermore, awareness of the state of response to therapy seems to be an important psychological factor as supported by the HQLQv2 scores obtained at the end of DAAs treatment therapy.

Table 3. Cronbach's coefficient and Spearman's correlation coefficients. Internal consistency and 12-weeks retest reliability of HQLQ inventory.

\begin{tabular}{lcc} 
& $\begin{array}{c}\text { Cronbach's } \alpha \\
\text { coefficientt }\end{array}$ & $\begin{array}{c}\text { Retest } \\
\text { reliability } \\
\text { (after 12 weeks) }\end{array}$ \\
Physical functioning (PF) & 0.95 & $0.683^{* *}$ \\
Role-physical (RP) & 0.95 & $0.479^{* *}$ \\
\hline Bodily pain (BP) & 0.88 & $0.51^{* *}$ \\
General health (GH) & Not reliable & Ns \\
\hline Vitality (VT) & Not reliable & Ns \\
Social functioning (SF) & Not reliable & Ns \\
\hline Role-emotional (RE) & 0.944 & $0.454^{* *}$ \\
Mental health (MH) & Not reliable & Ns \\
\hline Health distress (HD) & 0.9 & $0.548^{* *}$ \\
Positive well-being (PWB) & 0.86 & $0.537^{*}$ \\
\hline Hepatitis-specific limitations (HLIM) & 0.95 & $0.483^{* *}$ \\
Hepatitis-specific health distress (HHD) & 0.94 & $0.619^{* *}$ \\
\hline
\end{tabular}

\section{References}

Alhaji, M. M., Johan, N. H., Sharbini, S., Abdul Hamid, M. R., Khalil, M., Tan, J., Naing, L., \& Tuah, N. (2018). Psychometric Evaluation of the Brunei-Malay SF-36 version 2 Health Survey. Asian Pacific Journal of Cancer Prevention, 19(7), 1859-1865.

American Association for the Study of Liver Disease (AASLD). (2017). Hepatitis C guidance: AASLD-IDSA recommendations for testing, managing, and treating adults infected with hepatitis C virus. Hepatology, 62, 932-954.

Bansal, S., Singal, A. K., McGuire, B. M., \& Anand, B. S. (2015). Impact of all oral anti-hepatitis $\mathrm{C}$ virus therapy: A meta-analysis. World Journal of Hepatology, 7(5), 806-813.

Bartko, J. J. (1966). The intraclass correlation coefficient as a measure of reliability. Psychological Reports, 19(1), 3-11.

Bayliss, M. S., Gandek, B., Bungay, K. M., Sugano, D., Hsu, M. A., \& Ware, J. E., Jr (1998). A questionnaire to assess the generic and disease-specific health outcomes of patients with chronic hepatitis C. Quality of Life Research, 7(1), 39-55.

Belfer, I. (2017). Pain in women. Agri, 29(2), 51-54.

Bernstein, D., Kleinman, L., Barker, C.M., Revicki, D.A. \& Green, J. (2002). Relationship of health-related quality of life to treatment adherence and sustained response in chronic hepatitis $\mathrm{C}$ patients. Hepatology, 35, 704-708.

Bertino, G., Ardiri, A., Proiti, M., Rigano, G., Frazzetto, E., Demma, S., Ruggeri, M. I., Scuderi, L., Malaguarnera, G., Bertino, N., Rapisarda, V., Di Carlo, I., Toro, A., Salomone, F., Malaguarnera, M., Bertino, E., \& Malaguarnera, M. (2016). Chronic hepatitis C: This and the new era of treatment. World Journal of Hepatology, 8(2), 92-106.

Bertino, G., Malaguarnera, G., Frazzetto, E., Sciuto, A., Inserra, G., Zanghì, G. N., \& Malaguarnera, M. (2018). Responsibility of hepatitis $\mathrm{C}$ virus in the development of hepatocellular carcinoma: From molecular alterations to possible solutions. World Journal of Hepatology, 10(6), 448-451.

Bethea, E.D., Chen, Q., Hur, C., Chung, R.T. and Chhatwal, J. (2018). Should we treat acute hepatitis C? A decision and costeffectiveness analysis. Hepatology, 67(3), 837-846.

Bullinger, M., Alonso, J., Apolone, G., Leplège, A., Sullivan, M., Wood-Dauphinee, S., Gandek, B., Wagner, A., Aaronson, N., Bech, P., Fukuhara, S., Kaasa, S., \& Ware, J. E., Jr (1998). Translating health status questionnaires and evaluating their quality: the IQOLA Project approach. International Quality of Life Assessment. Journal of Clinical Epidemiology, 51(11), 913-923.

Cabibbo, G., Celsa, C., Calvaruso, V., Petta, S., Cacciola, I., Cannavò, M. R., Madonia, S., Rossi, M., Magro, B., Rini, F., Distefano, M., Larocca, L., Prestileo, T., Malizia, G., Bertino, G., Benanti, F., Licata, A., Scalisi, I., Mazzola, G., Di Rosolini, M. A., Alaimo, G., Averna, A., Cartabellotta, F., Alessi, N., Guastella, S., Russello, M., Scifo, G., Squadrito, G., Raimondo, G., Trevisan, Craxì, A., Di Marco, V., Cammà, C.,Rete Sicilia Selezione Terapia - HCV (RESIST-HCV) and Italian Liver Cancer (ITA.LI.CA.) Group (2019). Direct-acting antivirals after successful treatment of early hepatocellular carcinoma improve survival in HCV-cirrhotic patients. Journal of Hepatology, 71(2), 265-273.

Cabibbo, G., Petta, S., Calvaruso, V., Cacciola, I., Cannavò, M. R., Madonia, S., Distefano, M., Larocca, L., Prestileo, T., Tinè, F., Bertino, G., Giannitrapani, L., Benanti, F., Licata, A., Scalisi, I., Mazzola, G., Cartabellotta, F., Alessi, N., Barbàra, M., 
Russello, M., Scifo, G, Squadrito, G., Raimondo, G., Craxì, A., Di Marco, V., Cammà, C., Rete Sicilia Selezione Terapia HCV (RESIST-HCV) (2017). Is early recurrence of hepatocellular carcinoma in HCV cirrhotic patients affected by treatment with direct-acting antivirals? A prospective multicentre study. Alimentary Pharmacology \& Therapeutics, 46(7), 688695.

Calvaruso, V., Cabibbo, G., Cacciola, I., Petta, S., Madonia, S., Bellia, A., Tinè, F., Distefano, M., Licata, A., Giannitrapani, L., Prestileo, T., Mazzola, G., Di Rosolini, M.A., Larocca, L., Bertino, G., Digiacomo, A., Benanti, F., Guarneri, L., Averna, A., Iacobello, C., Magro, A., Scalisi, I., Cartabellotta, F., Savalli F., Barbara, M., Davì, A., Russello, M., Scifo, G., Squadrito, G., Cammà, C., Raimondo, G., Craxì, A., Di Marco, V., Rete Sicilia Selezione Terapia-HCV (RESIST-HCV) (2018). Incidence of Hepatocellular Carcinoma in Patients With HCV-Associated Cirrhosis Treated With Direct-Acting Antiviral Agents. Gastroenterology, 155(2), 411-421.e4.

Calvaruso, V., Cacciola, I., Licata, A., Madonia, S., Benigno, R., Petta, S., Bronte, F., Conte, E., Malizia, G., Bertino, G., Distefano, M., Montineri, A., Digiacomo, A., Alaimo, G., Cacopardo, B., Davì, A., Guarneri, L., Scalisi, I., Colletti, P., Cartabellotta, F., Portelli, V., Prestileo, T., Averna, A., Iacobello, C., Mondello, L., Scifo, G., Russello, M., Squadrito, G., Raimondo, G., Cammà, C., Craxì A., Di Marco, V., RESIST-HCV (Rete Sicilia Selezione Terapia-HCV) (2019). Is Transient Elastography Needed for Noninvasive Assessment of High-Risk Varices? The REAL Experience. The American Journal of Gastroenterology, 114(8), 1275-1282.

Caponnetto, P. (2018). Psychological and psychopathological sequelae in cardiovascular acute disease. Mental Illness, 10(2), 7887.

Caponnetto, P., Lai, C., Maglia, M., \& Cosci, F. (2020). What clinical and health psychology tell to internists and emergency physicians about harm reduction, addiction and asthma? Internal and Emergency Medicine, 15(4), 571-572.

Corsaro, L.S., \& Ragusa, R. (2018). Oral direct acting agent clinical trials for Hepatitis C Virus infection: an updated metaanalysis. EC Gastroenterology and Digestive System, 5(6), 447-455.

Di Matteo, M., Lepper, H.S., \& Croghan, T.W. (2000). Depression is a risk factor for noncompliance with medical treatment: Meta-analysis of the effects of anxiety and depression on patient adherence. Archives of Internal Medicine, 160(14), 2101-7.

Ebrahim, S. (1995). Clinical and public health perspectives and applications of health-related quality of life measurement. Social Science and Medicine, 41, 1383-94.

European Association for the Study of the Liver (EASL). (2018). EASL Recommendations on Treatment of Hepatitis C 2018. Journal of Hepatology, 69(2), 461-511.

Gold, M.R., Patrick, D.L., Torrance, G.W., Fryback, D., Hadorn, D.C., et al. (1996). Identifying and valuing outcomes. In: Gold MR, Siegel JE, Russell LB, Weinstein MC, editors. Cost-effectiveness in health and medicine. Oxford: Oxford University Press.

Horsmans, Y. (2006). Interferon-induced depression in chronic hepatitis C. The Journal of Antimicrobial Chemotherapy, 58(4), 711-713.

Katon, W., Lin, E.H.B. \& Kroenke, K. (2007). The association of depression and anxiety with medical symptom burden in patients with chronic medical illness. General Hospital Psychiatry, 29(2), 147-55.
Keefe, B. (2007). Interferon-induced depression in hepatitis C: an update. Current Psychiatry Reports, 9(3), 255-261.

Kuna, L., Jakab, J., Smolic, R., Wu, G. Y., \& Smolic, M. (2019). HCV Extrahepatic Manifestations. Journal of Clinical and Translational Hepatology, 7(2), 172-182.

Lins, L., \& Carvalho, F. M. (2016). SF-36 total score as a single measure of health-related quality of life: Scoping review. SAGE open medicine, 4, 2050312116671725.

Mandorfer, M., Payer, B.A., Scheiner, B., Breitenecker, F., Aichelburg, M.C., Grabmeier-Pfistershammer, K., Rieger, A., Trauner, M., Peck-Radosavljevic, M., Reiberger, T. (2014). Health-related quality of life and severity of fatigue in $\mathrm{HIV} / \mathrm{HCV}$ co-infected patients before, during, and after antiviral therapy with pegylated interferon plus ribavirin. Liver International, 34(1):69-77.

Maruish ME (Ed.). (2011). User's Manual for the SF-36v2 Health Survey (3rd ed.), QualityMetric Incorporated, Lincoln, RI.

McHutchison, J. G., Manns, M., Patel, K., Poynard, T., Lindsay, K. L., Trepo, C., Dienstag, J., Lee, W. M., Mak, C., Garaud, J. J., Albrecht, J. K., \& International Hepatitis Interventional Therapy Group (2002). Adherence to combination therapy enhances sustained response in genotype-1-infected patients with chronic hepatitis C. Gastroenterology, 123(4), 10611069.

Peasgood, T., Brazier, J., Mukuria, C., \& Rowen, D. (2014). A conceptual comparison of well-being measures used in the UK. Policy Research Unit in Economic Evaluation of Health and Care Interventions. Universities of Sheffield \& York. EEPRU Research Report 026. Policy paper/document 01/09/2014.

Pieretti, S., Di Giannuario, A., Di Giovannandrea, R., Marzoli, F., Piccaro, G., Minosi, P., \& Aloisi, A. M. (2016). Gender differences in pain and its relief. Annali dell'Istituto Superiore di Sanità, 52(2), 184-189.

Polo, M. L., \& Laufer, N. (2017). Extrahepatic manifestations of $\mathrm{HCV}$ : the role of direct acting antivirals. Expert Review of Anti-Infective Therapy, 15(8), 737-746.

Quelhas, R., \& Lopes, A. (2009). Psychiatric problems in patients infected with hepatitis $\mathrm{C}$ before and during antiviral treatment with interferon-alpha: a review. Journal of Psychiatric Practice, 15(4), 262-281.

Ragusa, R., Bertino, G., Bruno, A., Frazzetto, E., Cicciu, F., Giorgianni, G., \& Lupo, L. (2018). Evaluation of health status in patients with hepatitis c treated with and without interferon. Health and Quality of Life Outcomes, 16(1), 17.

Scheiner, B., Schwabl, P., Steiner, S., Bucsics, T., Chromy, D., Aichelburg, M. C., Grabmeier-Pfistershammer, K., Trauner, M., Peck-Radosavljevic, M., Reiberger, T., \& Mandorfer, M. (2016). Interferon-free regimens improve health-related quality of life and fatigue in HIV/HCV-coinfected patients with advanced liver disease: A retrospective study. Medicine, 95(27), e4061.

Ware, J. E., Jr, Kosinski, M., Bayliss, M. S., McHorney, C. A., Rogers, W. H., \& Raczek, A. (1995). Comparison of methods for the scoring and statistical analysis of SF-36 health profile and summary measures: summary of results from the Medical Outcomes Study. Medical care, 33(4 Suppl), AS264-AS279.

Ware, J. E., Jr, \& Sherbourne, C. D. (1992). The MOS 36-item short-form health survey (SF-36). I. Conceptual framework and item selection. Medical care, 30(6), 473-483.

Wei, L., \& Huang, Y. H. (2019). Long-term outcomes in patients with chronic hepatitis $\mathrm{C}$ in the current era of direct-acting antiviral agents. Expert review of anti-infective therapy, 17(5), $311-325$. 
WHO. (2014). Constitution of the World Health Organization. 48th ed. Basic documents of the World Health Organization. Geneva.

Younossi, Z., \& Henry, L. (2015). Systematic review: patientreported outcomes in chronic hepatitis $\mathrm{C}$ - the impact of liver disease and new treatment regimens. Alimentary
Pharmacology \& Therapeutics, 41(6), 497-520.

Zhou, K., Zhuang, G., Zhang, H., Liang, P., Yin, J., Kou, L., Hao, M., \& You, L. (2013). Psychometrics of the Short Form 36 Health Survey version 2 (SF-36v2) and the Quality of Life Scale for Drug Addicts (QOL-DAv2.0) in Chinese mainland patients with methadone maintenance treatment. PloS ONE, 